\title{
El valor argumentativo de la enumeración en las columnas periodísticas de Jaime Campmany. Una aproximación cualitativa
}

institucionales.us.es/ambitos/

\author{
Aurora García González \\ Universidad de Vigo \\ auroragg@uvigo.es \\ Lourdes Román Portas \\ Universidad de Vigo \\ romanportas@gmail.com
}

English Version: The argumentative value of the enumeration in the journalistic columns of Jaime Campmany. A qualitative approach

Este artículo aborda el estudio del valor argumentativo de la enumeración. Se realiza una aproximación cualitativa a la argumentación, uno de los elementos de la retórica clásica, como uno de los elementos de persuasión presentes en las columnas periodísticas de opinión. Desde esta concepción se ha realizado un análisis de la retórica del texto en la columna de opinión de Jaime Campmany titulada Escenas políticas, que se publicó en el diario ABC desde 1977 hasta 2005. La metodología

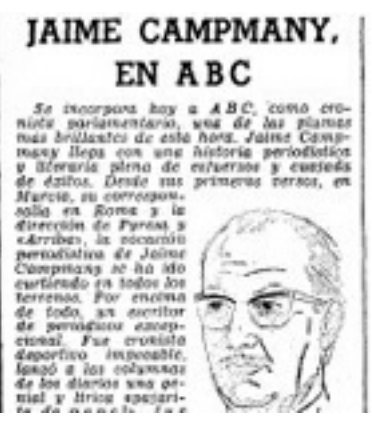
utilizada ha sido de carácter cualitativo. Dado el uso abundante y variado que hace de la figura de la enumeración, se llevó a cabo una clasificación del carácter de éstas para poder concluir el valor argumentativo de su uso, que pretende una mayor implicación del lector que mejore la eficacia comunicativa.

Palabras clave: retórica, periodismo, argumentación, columnismo, enumeración.

Abstract: This article deals with the study of the argumentative value of the enumeration. A qualitative approach to argumentation is made, one of the elements of classical rhetoric, as one of the elements of persuasion present in the journalistic columns of opinion. From this conception an analysis of the rhetoric of the text has been carried out in Jaime Campmany's opinion column entitled Political Scenes, which was published in the ABC newspaper from 1977 to 2005. The methodology used was of a qualitative nature. Given the abundant and varied use that makes the figure of the enumeration, a classification of the character of these was carried out in order to conclude the argumentative value of its use, which aims at a greater implication of the reader that improves the communicative effectiveness.

Keywords: rhetoric, journalism, opinion, argumentation, columnism, enumeration. 


\section{INTRODUCCIÓN}

Este artículo aborda el estudio del valor argumentativo de la enumeración.

Se realiza una aproximación cualitativa a la argumentación, uno de los elementos de la retórica clásica, como uno de los elementos de persuasión en las columnas periodísticas de opinión. El estudio se aborda desde una doble perspectiva, tanto desde la retórica clásica como desde la comunicación, pero con acento en esta última desde la que se emprende este trabajo. El objeto de estudio es determinar el valor argumentativo del uso de la enumeración en las columnas periodísticas de Campmany. Se trata de aproximarse en concreto, al empleo de esta figura retórica, para entender si la utilización que hace este permite optimizar la eficacia de la argumentación y por ende de la comunicación.

Este trabajo puede plantearse como proyecto de interés general para la comunidad científica debido a la necesidad, cada día más imperiosa, de captar la atención del lector en la prensa escrita; se trata de un momento en que la atención del lector está solicitada por múltiples nuevas tecnologías de la información y de la comunicación. En el seno de este proceso de cambio y sustitución de nociones y herramientas claves, este texto puede sumarse a la actual fase de investigación de la eficacia comunicativa del texto en un entorno multitarea. Según Berlanga y Martínez (2010), en efecto, es necesario repensar ciertas cuestiones; entre ellas, la construcción narrativa. De esta manera se puede resaltar el interés y la aportación que constituye este trabajo para el área de conocimiento del periodismo y la comunicación.

\section{Marco teórico}

\subsection{Retórica y Periodismo}

Durante el pasado siglo XX, proliferaron los estudios sobre retórica y su relación con el periodismo. Ambos, Retórica y Periodismo, utilizan la palabra para persuadir, por lo que revelan numerosos puntos en común. De hecho autores como Casasús y Núñez Ladevéze (1991), siguiendo a Lausberg, consideran el periodismo como heredero natural de la retórica clásica, ya que todo periodismo es esencialmente persuasivo. La información posee un valor instrumental sobre el que se sustentará la opinión. Se da, por tanto, una relación de interdependencia entre opinión e información, de modo que la primera utiliza estratégicamente la información que tiene (Núñez Ladevéze, 2007).

Si todo periodismo es persuasivo, cabe señalar que este carácter destaca sobre todo en las columnas de opinión. Este subgnénero se ha desarrollado preferentemente en las sociedades democráticas, que son el ámbito en el que tiene sentido hablar de retórica y persuasión. Como señala Jordi Berrio (1983) "el auge de los medios de comunicación de masas y de la vida democrática en un creciente número de países explican los esfuerzos que se están realizando [...] para rehabilitar la retórica clásica como arte de persuasión, porque en las sociedades contemporáneas, los métodos para obtener adhesión vuelven a tener una gran actualidad". En el contexto actual, determinado por el advenimiento de las nuevas tecnologías y la mediación de las redes sociales, se podría sostener con 
O'Halloran (2013) que se multiplican las facilidades para desarrollar nuevos marcos conceptuales con diferentes niveles de descripción, se ofrecen nuevas formas de conducir la investigación.

En este trabajo se parte de entender la retórica como el arte de la persuasión. Tiene contacto, por lo tanto, con elementos pragmáticos como los actos de habla (Albadalejo, 2000: 50; Albadalejo, 1994: 57-58; López García, 1985: 616-618) y puesto que el discurso retórico tiene una fuerza ilocutiva cuyas implicaciones conversacionales definen las estrategias comunicativas del emisor hacia el receptor (López García, 1985: 619; López Eire, 1999: 47-48), la conexión entre columna y retórica o, mejor, la consideración de la columna de opinión como un texto retórico resulta evidente.

El estudio del discurso periodístico va más allá, por tanto, del mero análisis del habla o de la lengua. "El discurso no es solamente un lenguaje, o conjunto de lenguajes, que se producen en el proceso social, sino que es, además, todo un acontecimiento expresivo que desborda la estricta acción comunicativa y que configura espacios de sentido para el individuo y los grupos sociales" (Benavides, 1997: 245). En la elaboración del mensaje periodístico propio de la columna confluyen diversas áreas del saber, aunque la confluencia con la retórica en el uso del lenguaje hace obligado su estudio en primer término.

La columna periodística tiene en principio una finalidad informativa, pero también tiene un objetivo persuasivo: la opinión expresada induce. Es precisamente en este punto donde hablar de retórica en relación con los textos periodísticos cobra sentido: esa intención de influir por medio de la palabra -o de otros elementos- es el fin último de la retórica y también de la columna. La columna periodística puede ser analizada como un tipo de texto, de extensión más o menos larga, pero en todo caso cuidadosamente elaborado, que presenta unas características propias.

Y para alcanzar esa finalidad persuasiva recurre con frecuencia a la argumentación, que tiene por fin llamar la atención y conseguir la adhesión del auditorio; lo primero por medio de la elocución y lo segundo por la invención y disposición, como elementos básicos. Dentro de la argumentación se da un continuum que va desde la máxima racionalidad, vinculada a la demostración, hasta la irracionalidad máxima que es el lugar que ocupa la sugestión. Si la primera la relacionamos con la columna analítica, con una argumentación explícita; la última está vinculada a la propaganda. Entre ambas se encuentra la argumentación implícita, en la que entra con fuerza la afectividad y que podemos vincular al tipo de columna personal (Angulo Ruiz, 1993)

La argumentación implícita se da en todo el periodismo, es lo que se llama lectura en mosaico del periodismo informativo, que consiste en la presentación jerarquizada de la información por la cual el medio influye en el lector al presentarle una información como más relevante, a la hora de elegir qué noticias se dan y cuáles no, o el lugar que ocupan en el periódico. Ante ella el lector está más indefenso ya que no es tan consciente de su presencia (Núñez Ladéveze, 2007). La argumentación implícita, asimismo conlleva una mayor presencia del emisor en el texto, mostrando cercanía y comunión con el lector. 
Manifiesta una gran proximidad efectiva, por medio de la coloquialidad, la polifonía y el empleo de abundantes figuras. Las ideas no son explícitas, sino que se desprenden del texto.

El lenguaje y los medios lingüísticos utilizados en los dos tipos de argumentación mencionados -explícita e implícita- en las columnas de opinión son también diferentes. La primera utiliza un lenguaje más objetivo, más neutral. Establece un distanciamiento entre autor-lector, entre emisor y receptor. El columnismo de Campmany, como se verá, se enmarca, sobre todo, en la argumentación implícita. En la lectura de sus columnas llama poderosamente la atención el uso de la enumeración, tanto la convencional como la caótica y este estudio quiere resaltar el valor argumentativo de esta figura: la enumeración.

\subsection{El valor argumentativo de la enumeración como figura en la elocutio}

En este estudio se aborda la enumeración como figura desde el punto de vista de la retórica, frente a otros estudios que tratan la enumeración como función textual desde la gramática del texto (Garcés Gómez, 1996 y 1997; Briz Gómez, 1998; Portolés Lázaro, 1998,2007; Casado Velarde 2000; Loureda Lamas 2000; Seco, Andrés y Ramos 2011, entre otros). Perelman y Olbrechts-Tyteca estudian las figuras retóricas en relación con la argumentación, con lo que pretenden mostrar "en qué y cómo el empleo de ciertas figuras determinadas se explica por las necesidades de la argumentación." (1989, 269-285). En este análisis se pretende mostrar el valor argumentativo de las distintas enumeraciones, incluso de la argumentación implícita.

Perelman y Olbrechts-Tyteca en la obra citada, estudian las diferentes figuras en referencia a la argumentación y las clasifican como figuras de elección, de presencia o de comunión. La enumeración forma parte de las figuras de presencia. "Entre las figuras que aumentan la presencia, las más sencillas se vinculan a la repetición, la cual es importante en la argumentación, mientras que en la demostración no aporta nada" (1989, 279). La presencia tiene como intención un efecto de amplificación, que se puede entender como el desarrollo oratorio de un tema, independientemente de la exageración con la que se asocia en general. La amplificación por la enumeración de las partes recuerda una argumentación cuasi-lógica. Un mecanismo para fomentar la presencia se produce por medio de la sinonimia, que repite una misma idea con ayuda de palabras diferentes, que sugieren una corrección progresiva o una corrección abreviada.

La enumeración ocupa, siempre de acuerdo con estos autores, un lugar entre las figuras de adición y amplificación. Por un lado, es posible considerarla como expresión sucesiva, lineal o jerárquica de las partes de que consta un todo. Por otro, desde el punto de vista sintáctico, apunta más allá de la oración, pues se trata de la unión de diversos enunciados que integran un texto. Puede considerarse también como un caso particular de una función más amplia denominada concatenación o adición. A la vez que existe una relación entre las partes (adición) se encuentra una relación entre éstas con el todo. Desde el punto de vista informativo, los argumentos introducidos por la enumeración pueden hallarse orientados o no (Loureda, 2000). 
También en relación con la semántica se establecen diferentes tipos de enumeraciones: la enumeración simple, la enumeración caótica, en la que se establecen juicios de valor de cada una de las partes y que se conoce como distribución, la enumeración correlativa y la enumeración recolectiva (cfr. Romera, Á. retórica.librodenotas.com). La semántica, como sucede con la retórica, ha sabido producir un andamiaje solido que permite un análisis estructurado y a la vez flexible para su adaptación a los cambios tecnológicos y sociales (De Marchis, 2013).

\subsection{La columna de opinión como género}

Ya se ha señalado que son abundantes los estudios sobre la columna de opinión que han proliferado en las últimas décadas; por un lado, para establecer una definición más allá de los rasgos paralingüísticos, y por otra para discernir la tipología que se da dentro de ellas (Gómez Calderón 2005; Lopéz Hidalgo, 2012; León Gross, 1996; López Pan 1995, 1996). También cabe observar el crecimiento cuantitativo de este género que ocupa cada vez un mayor número de espacio en la prensa, de modo que queda resaltada la actuación de los articulistas como ideólogos y una mayor perduración de sus contenidos en los debates públicos. Es Díaz Rojo quien destaca la escasez de racionalidad argumentativa con predominio de lo emocional en el periodismo opinativo español (Díaz Rojo, 2009).

Ciertamente, dentro del género columnístico, es necesario establecer una distinción entre la columna personal y la columna de análisis, distinción que lleva a establecer una diferente caracterización del modo de argumentar. La columna personal se diferencia de la columna analítica o interpretativa, porque esta última tiene como fin explicar las causas, consecuencias y el contexto de los hechos de actualidad que conforman la realidad, con desapasionamiento, mayor frialdad, aunque no de forma neutral o imparcial, mediante el análisis reflexivo y la elucubración intelectual, con predominio de lo descriptivo y analítico, por experto y especialista. Sin embargo, en España, para algunos autores, en este tipo de columnas se da la máxima subjetividad y por eso la ausencia de racionalidad argumentativa constituye uno de los rasgos definitorios más precisos del periodismo de opinión

Desde estos presupuestos es posible centrarse en uno de los recursos o mecanismos lingüístico-retóricos a través de los cuales se manifiesta esa emotividad y ausencia de racionalidad en el columnismo personal. Para el conjunto de estos recursos se utiliza el término "conceptismo periodístico" (Díaz Rojo, 2009), entre cuyos rasgos definitorios merece la pena destacar:

- Condensación y simplificación expresiva, que consiste en concentrar la mayor cantidad de información posible por medio de la utilización del número más reducido posible de palabras.

- Actitud provocadora. El autor intenta provocar al lector mediante opiniones audaces, insólitas, sorprendentes y transgresoras.

Ello conduce a una persuasión emotiva, que se caracteriza por la búsqueda de ideas pretendidamente deslumbrantes o ingeniosas, más que por la búsqueda del mero lucimiento ornamental, preciosismo estilístico del siglo de Oro. Entre las figuras retóricas y los mecanismos al servicio del conceptismo periodístico (Díaz Rojo, 2009) se encuentra la 
riqueza o acumulación léxico-semántica que revelan recursos como la sinonimia, la coordinación sinonímica y la enumeración, que es la que constituye el objeto de este trabajo.

Se toma como punto de partida la caracterización de la enumeración como figura que contribuye a acercar al lector una realidad, que señala partes, elementos, detalles concretos de un todo genérico. Como tal figura posee una gran fuerza expresiva y consigue impresionar al lector. Esas cadenas de palabras están llenas de viveza y valor descriptivo que facilitan la persuasión, pues mencionan aspectos específicos próximos al auditorio.

\subsection{La columna de opinión Escenas políticas de Jaime Campmany}

Este estudio se centra, como se ha establecido ya, en la columna de opinión Escenas políticas (1983) de Jaime Campmany que se publicaba en el diario ABC. La biografía de Campmany (Murcia, 10 de mayo de 1025- Madrid, 13 de junio de 2005) recorre tres cuartas partes del siglo XX y el primer lustro del siglo XXI. Vivió por tanto etapas muy dispares de la historia de España; el autor nace durante la dictadura de Primo de Rivera y su vida se desarrolla bajo la II República, los tres años de Guerra Civil, los casi 37 años de franquismo, la transición a la democracia y el comienzo de la monarquía parlamentaria, y los últimos 28 años de su vida ya en un estado democrático, precisamente, los años en que se ubica la publicación de esta columna.

Campmany es reconocido por la coherencia de sus ideas tanto por los amigos como por los adversarios. En la columna Escenas políticas se posicionó de una manera inequívoca en defensa de las ideas derechistas. Tanto en la época del franquismo como en el transcurso a la democracia, él mostró su libertad de pensamiento, de expresión y de respeto también a los que no pensaban como él, aunque en la columna política solía atacar a sus adversarios, apelando a la libertad de expresión y pensamiento. Sus ideas políticas son claras y ese talante hace que se cree una audiencia que ha compartido una historia común y que tiene también que dirigirse hacia una nueva historia común. Por lo general suele atacar todo nuevo intento de dividir España.

Escenas políticas nace el 26 de octubre de 1977, con el nombre entonces de Escenas parlamentarias, y se dilata hasta el mismo día del fallecimiento de Campmany. Por tanto, se ha escogido a un autor en un contexto periodístico determinado, en un momento de particular importancia para la vida democrática española, en el que cobran por ello más valor los textos argumentativos. El año escogido para este análisis tiene la particularidad de ser el primero en una etapa democrática en que gobierna el PSOE, por lo que los temas tratados en la columna son particularmente interesantes; entre otros, es el año de la expropiación de Rumasa, la legalización del aborto, etc.

Antes de comenzar el análisis de las columnas del año 1983, parece obligado realizar un acercamiento a las circunstancias históricas en que comenzaron a publicarse. Tras conseguir su aplastante triunfo en las elecciones del 28 de octubre de 1982, el PSOE se dispuso a consolidar y aprovechar su poder mediante una penetración decisiva en los diversos sectores de la sociedad. "Los socialistas diseñaron y pusieron en marcha un plan para el control totalitario de la enseñanza; prácticamente adoptaron el aborto libre; 
monopolizaron los medios de comunicación públicos, con creación proyectada de medios satélites falsamente privados; condicionaron a las empresas informativas y trataron de aplastar a los discrepantes de fondo mientras mantenían en su prensa oficiosa de propiedad privada actitudes críticas secundarias que disimularan el servil apoyo en lo principal" (De la Cierva, 1987: 372-373.) En año y medio de gestión el gobierno socialista controlaba el $55 \%$ de los recursos ajenos de la Banca y en cuatro años de legislatura habían aumentado en un $25 \%$ el índice de presión fiscal.

En este contexto, comienza la publicación en $A B C$ de la columna periodística Escenas parlamentarias de Campmany, epígrafe que cambiará por el de Escenas Políticas en los años siguientes.

\section{Metodología}

El objetivo principal del estudio es determinar el valor argumentativo del uso de la enumeración en las columnas de Campmany. La metodología utilizada ha sido de carácter cualitativo. Y la técnica de análisis empleada en el estudio, ha sido el análisis retórico. Tras la recogida en una base de datos de los ejemplos de diversas figuras retóricas utilizadas por el autor en el corpus objeto de estudio, se ha prestado atención al uso abundante y variado de la figura de la enumeración, lo que llevó a establecer una clasificación del carácter de la misma para poder concluir el valor argumentativo de su uso, que busca una mayor implicación del lector.

Desde mediados del siglo pasado se ha recuperado la noción primigenia de la retórica como uso persuasivo de la palabra. Seguimos a Lausberg, que considera el periodismo heredero directo de la retórica, no sólo en los géneros de opinión, sino en todo lo concerniente a lo periodístico. Desde esta concepción se ha realizado un análisis de la retórica del texto argumentativo en la columna de opinión de Jaime Campmany titulada Escenas políticas que se publicó en el diario $A B C$ desde 1977 hasta 2005. El trabajo se centra en el año 1983, y abarca un total de 265 columnas. El volumen de material disponible de este año, primero de la etapa socialista, pareció justificar la posibilidad de convertirlo en objeto único de estudio, sin descartar ulteriores ampliaciones de la investigación.

El análisis realizado en estas páginas ha tratado de valorar los siguientes aspectos:

- La coordinación semántica entre las partes: ruptura o no, lo que llevará a la enumeración caótica

- La igualdad categorial o funcional entre las mismas

Dentro de la amplificación, la enumeración no añade ideas, sino que multiplica conceptos; no expande el significado, sino que resulta acumulativa: únicamente aporta temas nuevos o subtemas; la vinculación de estos con el tema principal es menos estrecha que en el caso de la adición. En la enumeración caótica los elementos que la componen crean una acumulación incoherente, que refleja adecuadamente un estado anímico, una situación revuelta y efectivamente caótica (Spang, 2005). Las enumeraciones otorgan énfasis a la descripción, muchas de ellas terminan con un elemento hiperbólico o apoteósico, como se verá en algunos de los ejemplos que se han aportado. 
Tras proceder a establecer una clasificación de los ejemplos seleccionados, se ordenaron las posibilidades de la siguiente manera:

a) Serie enumerativa de carácter descriptivo con matriz implícita

b) Enumeración con reiteración de un elemento.

c) Series enumerativas con coincidencia semántica de términos que incluyen gradación.

d) Enumeración caótica con final apoteósico de carácter hiperbólico.

e) Enumeraciones de series contrapuestas caóticas. No guardan relación entre sí y remarcan el absurdo.

f) Acumulación de elementos oracionales, correlativos en el significado, forma o función gramatical. Su propósito es enfático o simplemente enumerativo.

g) Series enumerativas negativas: ni

h) Series enumerativas de acciones

En todas las categorías se incluyeron ejemplos de uso habitual en el autor, que proceden de una exhaustiva revisión de las columnas referidas.

\section{Resultados}

Desde esta concepción metodológica se ha realizado un análisis de la retórica del texto argumentativo en la columna de opinión de Jaime Campmany titulada Escenas políticas que se publicó en el diario $A B C$ desde 1977 hasta 2005, con los siguientes resultados:

\subsection{Serie enumerativa de carácter descriptivo con matriz implícita}

Este primer grupo presenta una serie enumerativa de carácter descriptivo en que la matriz de lo que se está describiendo está implícita. La fuerza enumerativa radica en la repetición de la estructura sintáctica y el carácter asindético de la enumeración con elipsis verbal que agiliza también la misma enumeración.

"El embarazo, interrumpido. La compatibilidad, quebrantada. La peseta, mordida. La verja, rota. El país, hendido. El personal, deshecho. Y el lirio, cortado. O sea, la ética, la estética, la poética y la dietética." (El lirio cortado, ABC 11.02.1983)

El ejemplo anterior hace una descripción de la situación de España en aquellos momentos, aludiendo a diferentes temas: aborto, trabajo, economía, situación de Gibraltar, etc. Todos ellos son temas descritos por el participio que acompaña a cada uno de los sintagmas nominales. A los subtemas se les añade la situación general del país y de los ciudadanos, para concluir con un término apoteósico y absurdo, que sólo tiene sentido en esta columna por el modo anecdótico con que había comenzado su texto. Como se advierte, en la enumeración se dan también juicios de valor. En este mismo sentido se encuentra el siguiente ejemplo que enumera por medio del empleo de distintos elementos: participios, frases hechas, adverbios, sintagmas preposicionales, pero en construcciones paralelas funcionalmente y en las que hay elipsis verbal y que incluyen un final apoteósico irónico: 
"Estos chicos se las prometían felices, con una derecha desunida, Fraga bajo techo, Adolfo desinflado, Landelino a dos velas, los socialdemócratas dentro, el comunismo hecho añicos, los empresarios castigados, los diez millones de votos en las urnas. Mitterrand en la Bastilla, Papandreu en el Partenón y Calviño en Prado del Rey." (Babor y estribor, ABC 22.02.1983)

En el siguiente ejemplo viene reforzada la descripción no sólo por la reiteración de la estructura sintáctica, sino también por cierta relación semántica entre los sustantivos que refuerza el sentido del texto en la primera parte del mismo. Además el artículo concluye con una enumeración caótica en la que se insertan elementos no esperados, por anacrónicos, y finaliza el escrito con un término inesperado, también con un fin apoteósico hiperbólico.

"La falta de rigor. El desprecio a las normas. El descuido de la previsión y el estudio. El desvío de la ciencia y la experiencia. No sólo arrollan la norma, la ética, el derecho, el trívium, el quadrivium, el digesto, las XII tablas, el "ius canonicum", los derechos adquiridos y la Biblia rústica. Todavía, si sólo arrollaran la Biblia en pasta, podríamos seguir leyéndola sin encuadernar. Y atropellan, en definitiva, la realidad." (El aviso, ABC 21.12.1983)

La siguiente enumeración asindética, combina una parte de la misma con gerundios y una segunda parte con participios, de manera que repite la estructura sintáctica:

(...) "con los médicos soltando el bisturí y colgando la bata, con los piquetes en las puertas de las sucursales, con los presos matándose en las cárceles, con los profesionales asustados, con los funcionarios combatidos, con los empresarios hostigados, con los políticos cubiertos de insultos." (Oda a la paciencia, ABC, 22.04.1983)

En ocasiones la enumeración presenta la misma estructura sintáctica: en este caso se trata de suplementos en los que el núcleo del sintagma nominal va acompañado por un complemento de nombre. La serie es asindética.

"A los socialistas el país se les ha poblado de ikurriñas separatistas, de empresas en quiebra, de parados coléricos, de pretendientes feroces - todos llegan con la escalera, que decía Guerra." (El sayal y la púrpura, $A B C, 5.09 .1983)$

El siguiente ejemplo repite la misma estructura que el anterior $y$, además, añade un elemento iterativo final, a modo de epífora.

"Me habla del viejo baúl de los recuerdos, de la camisa azul, de los campamentos de juventud, o sea, de la parafernalia del ancien regime, de la niñez del ancien regime." (Escribir, ABC, 19.06.1983)

Se da, en consecuencia, una estructura de presencia que viene marcada por la reiteración sintáctica.

\subsection{Enumeración con reiteración de un elemento}


Un segundo tipo de enumeración es la que muestra la reiteración del adjetivo para producir una mayor presencia. Un primer ejemplo sirve para mostrar el carácter peyorativo del adjetivo "sepia" que se refiere a diferentes ámbitos, y que acaba siendo también aplicado a un último término, "hipócritas", que rompe con la semántica anterior, así como el término "burgueses".

"Ahora resulta que lo de la zorra no sólo ha escandalizado a los periódicos sepia y a los cronistas sepia y a los burgueses sepia y a los hipócritas sepia. Parece que ha inquietado también al señor fiscal general del Estado, don Luis Burón, que es hombre que se pone los códigos sobre la cabeza, no con una mano, sino con las dos." (Carta de ajuste, ABC 2.05.1983)

"Esto, en el mapa. En la polémica ideológica, Rusia, el imperialismo soviético, o como queráis Ilamarlo, aprovecha la libertad del Occidente para mantener la predicación marxista, el apostolado marxista, los partidos marxistas y los intereses económico-político rusos. Por el contrario, en el Este, la predicación de la libertad no es posible. Allí, a quien predica la libertad, le cortan la voz. Total, que van ganando los sarracenos." ("El ajedrez", $A B C 28.10 .1983$ ) (en este ejemplo rompe la serie con el último elemento, pero insinúa con eso una identificación de los dos adjetivos: marxista-ruso).

Tierno, alcalde. El viejo profesor, viejo marxista, viejo ético, viejo sabio y viejo maestro es ya, también, viejo alcalde. (“El viejo alcalde”, $A B C$ 11.05.1983).

Estamos con la derecha "dura", la huelga "dura", la sentencia "dura" y la campaña "dura". Aquí, todo es duro, menos lo que tenemos en el bolsillo. Decían "Vamos a hacer que el país funcione", y ya no funcionan ni los Bancos, que es lo que ha funcionado toda la vida. (La semana mágica, ABC 30.04.1983).

"Y además, cuatrocientos autos sacramentales. $Y$ novelas, y poemas mayores y menores, entremeses, églogas, epístolas, loas, y la Biblia en verso, la vida en verso, la muerte en verso, el amor en verso, la fantasía en verso." (Una pasada por Lope, ABC 16.02.1983) (en este caso se reitera un sintagma preposicional).

Tal como se ha visto, la presencia se produce por medio de la sinonimia, que repite una misma idea con ayuda de palabras diferentes, que sugieren una corrección progresiva o una corrección abreviada.

\subsection{Series enumerativas con coincidencia semántica de términos que incluyen gradación}

En las siguientes series enumerativas es posible detenerse en la coincidencia semántica de sus términos, en los que se puede percibir también cierta gradación, bien ascendente o bien descendente. Este primer ejemplo muestra una acumulación polimembre asindética

"Las gentes de autoridad, de prestigio, de sabiduría, de buen criterio, han sido desterradas de ella. Sólo aparecen militantes reclutados de donde sea." (La conjura de los torpes, ABC 27.05.1983)

Los complementos preposicionales como complementos de nombre, muestran una correlación en el significado que se percibe como gradativa, desde la autoridad hasta el buen criterio. 
En el siguiente caso las expresiones hechas son sinonímicas. Y destaca también la serie enumerativa final en la que contrapone dos posturas, dos mundos, dos concepciones políticas, contrastando marxismo y democracia occidental.

"Si estar en el sitio del presidente del Gobierno supone hablar en el vacío, andarse por las ramas, salirse por la tangente y escaparse por los cerros de Úbeda, desde luego don Felipe González ha estado en su sitio. Estos socialistas nuestros no se aclaran y no nos dicen si quieren estar en la OTAN o en el marxismo de Nicaragua, en el Mercado Común o en el tercer mundo, en la democracia occidental o tomando caviar en Dubinin en la Semana de Moscú." (Comer palabras, ABC 24.09.1983)

En alguna ocasión, los adjetivos que califican al país muestran una relación semántica por pares. Esta relación semántica de cierta sinonimia tiene también el aludido efecto de presencia.

(...) "que España ha dejado de ser un país mágico, sorpresivo, singular y diferente. Ni Europa, ni Occidente, ni humanismo cristiano ni garambainas." (Carta al mamut, ABC 7.05.1983)

"Cuando ya este país sea un país de parados, de vacantes, de cesantes y huelguistas, y creamos que hemos dado con el gran invento de vivir sin trabajar, se nos morirá el burro." (La puerta del paraíso, ABC 25.11.1983)

Se trata, en este último caso, de una estructura polimembre de sintagmas preposicionales, con la excepción del último elemento de la relación. Son sustantivos relacionados por su significado con el mundo del trabajo.

En el siguiente ejemplo se encuentran por un lado una serie de adjetivos y una serie de sustantivos con significados afines, aunque los dos últimos manifiestan un sentido más negativo.

"Hay que aprender a ser hegemónicos. El jefe de los hegemónicos permanece algo inaccesible, inalcanzable, incontaminado de los errores de sus seguidores, secuaces, colaboradores, cómplices o paniaguados." (Los hegemónicos, ABC 20.05.1983)

"Estamos armando una zarabanda de héroes, de santos, de santones, de guerreros, de aventureros, de insignes y de indeseables. Mezclamos a unos con otros. Le quitamos una calle a Cervantes para dársela a Lumumba. Se le dedican calles a los terroristas. Se derriba la estatua de Franco por la razón de que un alcalde no coincidía ideológicamente con él. Vamos a terminar por llamar fascista al Cid y por quemar los retratos de Felipe II por facha. La ira política o el fanatismo político permite insultar al Papa Wojtyla, tratar a los obispos como a una horda de bárbaros, poner a Isabel la Católica entre las furcias ilustres y hablar de los santos como de giliflautas. Y viceversa." (Los mártires, ABC 21.10.1983)

Esta última es una enumeración polimembre de sintagmas preposicionales con más significados positivos (santos, héroes, guerreros, insignes) frente a los peyorativos (santones, aventureros, indeseables). Presenta también una enumeración en la que se aprecia un paralelismo en las construcciones que comienzan con infinitivo: insultar, tratar, poner, hablar) 


\subsection{Enumeración caótica con final apoteósico de carácter hiperbólico}

Sintácticamente la enumeración se da a diferente nivel. En este ejemplo el autor enumera personajes históricos, con otros actuales y ficticios, todos ellos como complementos directos.

"Que lo mismo se puede encontrar al conde de Benavente, a la sombra alargada de don Felipe II, al alcalde de Móstoles o a Pascual Duarte." (Bon soir, Europe, ABC 30.11.1983)

La siguiente enumeración caótica está a la altura del complemento de nombre y mezcla también personajes y elementos discordantes como los cohíbas de Fidel.

"Don Alfonso Guerra podría armar en Centroamérica la de no te menees, Pancha, y organizar en un santiamén una jarana histórica de Maximiliano, el viva Villa, el Che, el comandante Cero, la bahía guantamerana, el cura Merino y los cohíbas de Fidel." (Los viajeros, $A B C$ 1.06.1983)

Por último se muestra un ejemplo en el que la enumeración termina también con un elemento discordante, de nuevo marcando la apoteosis final: la cartera en la inopia.

"Don Fernando Morán se ha ido a Moscú a firmar papeles con los rusos y a explicarles que no estamos ni dejamos de estar en el Pacto Atlántico, sino todo lo contrario, y que nuestra política sufre el desgarro doloroso de tener la cabeza en Occidente, el corazón en Oriente y la cartera en la inopia." (Los viajeros, $A B C$ 1.06.1983)

Los ejemplos de esta enumeración caótica son los más abundantes y así lo mostramos también en los siguientes casos:

"Podríamos encontrarnos un día con que, a golpe de 200 escaños, estos señores acaban con la democracia, con la libertad, con el modelo de sociedad, con el sagrado de la Constitución, con el mismísimo Parlamento y con la Biblia en pasta." (El areópago, ABC 18.10.1983)

"La Medicina estaba en las "medidas políticas". Ahora, ese mismo coro de doctores se ha caído del burro y ya han comprobado que la transición a la democracia, la Constitución, el Estado, la Autonomía, el "lendakari”, las transferencias, las amnistías, las indemnizaciones, los viajecitos pagados a Oslo, las tolerancias y toros remilgos, no sirven para nada. O sea, que de estos médicos que nos han tocado en suerte se han dado cuenta de que el cáncer no se cura con aspirina." (El cáncer, $A B C$ 23.10.1983)

"El caso de don Fernando Abril Martorell requiere una monografía. Desde la vicepresidencia del Gobierno de don Adolfo Suárez organizó un barullo en el Estado, en la política, en la economía, en la Constitución y en la oratoria del cual aún no hemos empezado a salir. A la crónica de este tiempo, ha pasado como don Fernando el Caótico. $Y$ yo tengo escaso mérito en ello. Casi todos los méritos son suyos." (Fernandina, ABC 26.10.1983)

"Don Javier Solana se fue a los premios Mayte de teatro que se lo daban a Fernando Fernán-Gómez, por lo de las bicicletas. El señor ministro aprovechó la solemne ocasión para poner la primera, la segunda, la tercera o la catorcena piedra de la revolución 
gramatical. No podemos quedarnos en la revolución económica, en la revolución social, en la revolución política, en la revolución sexual y en la revolución ciclista. Hay que hacer también la revolución gramatical. Yo no pude estar allí, que a veces me pierdo las mejores. Estaba buscando las obras completas de Lope, que no sé dónde las habrá encontrado don Alfonso Guerra. Estos socialistas lo encuentran todo: los cargos, las mamandurrias, los abortos clandestinos, las corrupciones, los diez millones de votos y el polvo debajo de las alfombras. Un día de estos encuentran el Paraguay." (Oradores a la violeta, $A B C$ 19.02.1983)

"El currante, además de su familia natural, a la que se van uniendo consanguíneos y afines en apuros de liquidez, o sea, que se han quedado con una mano atrás y otra delante, y en algunos casos la que te sobreviene si has tenido la imprevisión de romper el vínculo, tienen que mantener también al parado, al jubilado por sazón, al jubilado por anticipo, al rebajado por enfermo, al huelguista de cada siesta, tarde o mañana, al manifestante y al asambleísta, al líder del sindicato, y, ahora, a la "jai" que quiere quitarse al niño." (Trabajar en el paro, $A B C$ 20.11.1983)

"Luego vienen las lamentaciones, los discursos, las acusaciones mutuas o las lágrimas de cocodrilo." (Volver de Babia, ABC 30.10.1983)

\subsection{Enumeraciones de series caóticas que manifiestan duda}

La siguiente serie de ejemplos se refiere a las enumeraciones caóticas. Los términos enumerados no guardan relación entre sí y remarcan el absurdo.

"Parece como si estuviéramos buscando algo en el centro de la Tierra, no sé, terroristas, petróleo, oro, tumbas etruscas, restos arqueológicos, el incendio mineral y telúrico donde nacen los volcanes (...). No sé lo que estaremos buscando: el cambio, el recambio, la panacea, la democracia perdurable. (...) En agujeros, cuevas, zulos y escondrijos. O sea, en madrigueras." (El agujero, $A B C$ 1.05.1983)

"Hay que esperar. Así que lo que tenemos que hacer es armarnos de paciencia. Hay que esperar a ver en qué queda todo esto, no sé, los misiles, el Congreso socialista, la "cumbre" de Atenas, el relanzamiento económico, la operación Roca, la sentencia de Rumasa, la Navidad de Pau, las elecciones vascas, la salud de Andropov, el cese de Calviño, las tribulaciones de Morán, los silencios de Guerra, el cierre de Sagunto, la movida comunista, las aproximaciones del duque, la sucesión de Ferrer Salat, las medidas antiterroristas, la tertulia de los liberales, la autonomía gallega, la reforma militar, el juicio de Guernica, la reconversión industrial y el himno de Madrid." (Sala de espera, ABC 29.11.1983)

Queda patente en estos ejemplos, que se manifiesta además la duda y el desconcierto.

\subsection{Acumulación de elementos correlativos en el significado, forma o función gramatical}

Así, el siguiente ejemplo presenta una serie adjetiva con un significado contrapuesto a la serie sustantiva que se presenta además con una estructura bimembre. 
"Nos habían prometido una España floral, paradisíaca, edénica y hasta ética, y resulta que nos están metiendo en un huerto de cactus y de cardos borriqueros, de ortigas y jaramagos. Han llenado el país de espinas y pinchos y el vecindario anda ya como los erizos." (Cerca de la primavera, ABC 12.03.1983)

En este otro se aprecia una serie de sustantivos en relación de significado correlativa.

"Pero ya estamos de regreso. La euforia de aquel octubre del año pasado, con bailes en las plazas, banderas en las calles y entusiasmo en los gritos, se van convirtiendo inexorablemente en decepción, en desengaños, en quejas y en protestas." (Con la voz de morir, ABC 20.12.1983)

Y en las siguientes enumeraciones encontramos diversas acumulaciones, en combinación adjetiva, trimembre y bimembre. El primero concluye el párrafo con dos series contrapuestas disyuntivas, en las que el autor acumula dos series enumerativas de adjetivos que utiliza para enfrentar dos posibilidades de socialismo:

"De cualquier modo, y sin necesidad de elevar al tamaño de las grandes magnitudes ideológicas, históricas o políticas las declaraciones, las declaraciones occidentales y capitalistas de don Felipe González - que todavía no sabemos bien si tienen el carácter de confesiones o de concesiones-, parece claro que el socialismo español ha terminado por enfrentarse claramente con su gran dilema: o constituirse en socialismo democrático, occidental, moderado, moderno, respetuoso con las libertades políticas y económicas o mantener el tipo de socialismo revolucionario, utópico, igualitario, totalitario, estatalizador, marxista, prosoviético que le llega desde sus raíces." (La crisis del socialismo, ABC 26.06.1983)

"Ofrecer una igualdad de oportunidades a los escolares está antes que desvelarse por conceder tratos exquisitos y remilgos policiales, judiciales y sociales a los drogadictos, a las abortistas, a los holgazanes, a los destructores, a los abusones de la libertad propia en deterioro de la ajena, a los delincuentes." (La escuela, ABC 12.10.1983)

Este caso presenta una estructura trimembre en los adjetivos y una serie enumerativa sustantiva asindética.

"Cuando ya este país sea un país de parados, de vacantes, de cesantes y huelguistas, y creamos que hemos dado con el gran invento de vivir sin trabajar, se nos morirá el burro." (La puerta del paraíso, ABC 25.11.1983)

De nuevo una estructura polimembre de sintagmas preposicionales, con la excepción del último elemento de la relación. Se trata de una serie de sustantivos relacionados en su significado con el mundo del trabajo.

"Al viejo profesor y ya viejo alcalde hay que reconocerle el raro don de la apacibilidad. Cuando casi todos chillan, saltan, se engrescan, se despeinan y se inquietan, el viejo profesor baja el tono de voz, mueve la mano con gesto de predicador tímido, eleva los ojos, pronuncia palabras corteses, ensaya latines, acude a recibir las bicicletas en un rapto de modernidad y futurismo, palmea la mejilla de Cristina Almeida, se va un rato con Nicolás y otro rato con Marcelino, habla benévolamente de los políticos como si fueran 
examinandos no muy brillantes, imparte una dosis tolerable de demagogia de clase, se marca un bailongo con la negra y derrama sobre el azogue de la vida política una especie de bálsamo tranquilizante y somnífero." (El viejo alcalde, ABC 11.05.1983)

El ejemplo muestra una enumeración en la que el autor contrapone dos actitudes: en la primera sólo aparecen los verbos dando una sensación trepidante frente a la serie más pausada en la que describe el modo de actuar de Tierno, con complementos del verbo, que hace pausada la descripción y transmite así la apacibilidad que le atribuye.

\subsection{Series enumerativas negativas: ni}

El autor ofrece en este caso una enumeración polisindética de sustantivos.

"Ni neutralismo, ni pacifismo, ni cultura, ni ética, ni utopía. Y si nos descuidamos, ni socialismo." (El fin de la utopía, ABC 2.06.1983)

El siguiente ejemplo evidencia una serie de enumeraciones caóticas con elementos insólitos e ideas contrapuestas.

"Ni referéndum, ni puestos de trabajo, ni dimisiones fulminantes, ni el oro de Moscú, ni visita de Fidel Castro, ni infraestructura cultural, ni éticas, ni laicismos. Al revés, Wall Street, misiles, aumento del paro, fraques, dólares, y para compensar la introducción al aborto, a creer en los milagros y a querer presidir las procesiones." (El fin de la utopía, $A B C$ 2.06.1983)

O bien ejemplifica una enumeración polisindética de oraciones que termina con un elemento discordante.

"Ni siquiera sabemos si pertenecemos ya a Occidente... ni hacemos el referéndum ni entramos en la OTAN, ni salimos de la OTAN, ni nos quedamos en Occidente, ni nos vamos a Oriente, ni tiramos por la calle del medio." (Aprenderse el papel, ABC 17.03.1983)

\subsection{Series enumerativas de acciones}

Se incluye una muestra de enumeración paralelística de construcción: verbo más complemento directo.

"Pero no hace tanto tiempo que Europa nos quemaba vivo a Miguel Servet, colgaba a Mussolini cabeza abajo, hacía jabón con la grasa de los judíos, organizaba la fiesta bárbara de la guerra o levantaba el muro de Berlín." (Bon soir, Europe, ABC 30.11.1983)

Y un último ejemplo de enumeración asindética de oraciones pasivas reflejas.

“¿Y qué sucede luego? Que los demás hacen todo lo contrario. Se presiona a la Banca, se recela del Ejército, se buscan conflictos con la Iglesia, se intenta disminuir la función de la Justicia, se bordea la Constitución." (El intocable, ABC 12.11.1983)

\section{Conclusiones}

Del estudio realizado en páginas anteriores ha sido posible establecer, al menos las siguientes conclusiones: 
El género columnístico, que se ha estudiado como texto retórico por su intención persuasiva, manifiesta esta vertiente a través del uso de diversas figuras retóricas con valor argumentativo en la elocutio. Es precisamente ese valor el que muestra la diferencia entre el simple ornato, figura de estilo y el valor argumentativo de la figura retórica. $Y$ es precisamente en la elocutio donde destaca Campamny, por su gran capacidad versificadora, por el uso de las figuras retóricas, especialmente abundante, en lo que se refiere a la enumeración y la enumeración caótica y, en general, por las figuras de acumulación. En ellas muestra el énfasis, y la contención de la cantidad de temas y de argumentos que podría desarrollar. El léxico y el diferente uso de los niveles del lenguaje son de un dominio total.

Campmany es un escritor culto, con un amplísimo dominio de vocabulario, que usa de manera precisa. Y, al mismo tiempo, destaca el uso del lenguaje coloquial que se manifiesta no sólo en el vocabulario, sino en el uso abundante que hace de los refranes, los modismos, etc., a veces de forma parafraseada, a veces literal. Esta capacidad del uso coloquial y preciso del lenguaje es uno de los principales elementos que permiten el acercamiento a sus lectores.

El análisis realizado ha permitido también entrever valores culturales que se desglosan en un discurso, en este caso retórico, y cómo se vehicula la transmisión de los mismos; se descubre por tanto un acercamiento a la eficacia comunicativa de determinadas herramientas. Efectivamente se trata de un fenómeno comunicativo, mediado por la cultura del propio comunicador, que explota al máximo las diferentes formas de enumeración, uno de los principales elementos del discurso retórico.

La metodología empleada para el análisis de los textos desde una perspectiva argumentativa de la comunicación ha servido como pauta para explicar el éxito del resultado: La enumeración, efectivamente enriquece la comprensión, los contenidos y los procesos dialógicos. El autor asume diversos usos de la enumeración, como se ha comprobado en la clasificación que se llevó a cabo en el estudio, y con ello se manifiestan como figura de presencia el valor enfático y la exageración, sobre todo en las enumeraciones caóticas

Otro elemento de calidad que destaca en las columnas de Campmany es el uso de las figuras de acumulación y especialmente la enumeración, que muestra contención, ya que la columna tiene un espacio limitado, pero al mismo tiempo sugiere temas y argumentos que no desarrolla, pero con los que implica al lector para que saque sus propias conclusiones. En la enumeración se muestran tanto la reiteración sintáctica de estructuras como la vinculación semántica de las ideas o temas. La enumeración, y la enumeración caótica dentro de ella, son uno de los recursos más frecuentes y abundantes en las columnas de Campmany.

Destaca también el valor semántico en las enumeraciones en las que existe gradación y las que contraponen series enumerativas de carácter positivo que se desdicen, por otras de valor negativo. Se puede concluir además que la enumeración encaja en la prosa y estilo de Campmany por su gran dominio y riqueza de vocabulario, que le permite enjaretar unos temas con otros formando una cascada de ideas. 


\section{Referencias bibliográficas}

\section{Libros}

ALBADALEJO, T. (2000). Retórica. Madrid: Síntesis D.L.

ALBADALEJO, T. y CHICO RICO, F. (1994) La teoría de la crítica lingüística y formal. Teoría y crítica literaria. Coord. Pedro Aullón de Haro, 175-293.

BENAVIDES, J. (1997). Lenguaje publicitario. Madrid: Síntesis.

BERRIO, J. (1983) Teoría social de la persuasión. Barcelona: Ed. Mitra.

BRIZ GÓMEZ, A.(1998) El español coloquial en la conversación. Barcelona: Ariel.

CASASÚS GURI, J.M. y NÚÑEZ LADEVÉZE, L. (1991) Estilo y géneros periodísticos. Barcelona. Ariel

DE LA CIERVA, R. (1987) La derecha sin remedio. Barcelona. Plaza.

LAUSBERG, H. (1966). Manual de retórica literaria (Tomo I). Madrid: Gredos.

LEÓN GROSS, T. (1996). El artículo de opinión. Barcelona: Ariel.

LÓPEZ HIDALGO, A. (2012) La columna. Periodismo y literatura en un género plural. Zamora: Comunicación Social.

LÓPEZ PAN, F. (1996). La columna periodística, teoría y práctica: el caso de "Hilo directo". Pamplona: Eunsa.

PERELMAN, CH. y OLBRECHTS-TYTECA, L. (1989) Tratado de la argumentación. Nueva Retórica. Editorial Gredos. Madrid

PORTOLÉS LÁZARO, J, (1998) Marcadores del discurso, Barcelona: Ariel.

SECO, M., ANDRÉS, O. \& RAMOS, G. (2011). Diccionario Español Actual. Madrid: Aguilar.

SPANG, K. (2005) Persuasión. Fundamentos de retórica. Pamplona: Eunsa

\section{Capítulos de libros}

CASADO VELARDE, M. (2000) "Las formas fulano, mengano, zutano, perengano y su funcionamiento como ordenadores del discurso" en CARBONERO CANO, P.; CASADO VELARDE, M. y GÓMEZ

MANZANO, P. (eds): Lengua y discurso. Estudios dedicados al Profesor Vidal Lamíquiz. Madrid: Arco/Libros, 2000.183-195.

LÓPEZ GARCÍA, A. (2016). "Metodología del discurso en la oralidad" en Bañón Hernández, Espejo Muriel y Herrero Muóz-Cobo. (eds.): Oralidad y análisis del discurso. Almería. Ediciones Universitarias.

LÓPEZ PAN, F. (1995). Recopilador y "Estudio introductorio" en 70 columnistas de la 
prensa española. Pamplona: Eunsa.

\section{Artículos en revistas}

ANGULO RUIZ, L. (1993) "Dos estrategias retóricas en el periodismo de opinión." Comunicación estudios venezolanos de comunicación, n. 84, pp. 49-55

BERLANGA, I. \& MARTÍNEZ, E. (2010). "Ciberlenguaje y principios de retórica clásica. Redes sociales: el caso Facebook". Enl@ ce 7.2, 47-61.

De MARCHIS, G. (2013). "La retórica y el análisis de la tecnología y de la sociedad actuales. Presentación". Revista ICONO14. Revista científica de Comunicación y Tecnologías emergentes, 11(1), 1-4.

DÍAZ ROJO, J. A. (2009) "El conceptismo como recurso retórico en columnas." Estudios sobre el Mensaje Periodístico, n. 15, pp. 207-226.

GARCÉS GÓMEZ, M. P. (1996) “La enumeración en el discurso oral”, Español Actual 66.

- (1997) Procedimientos de ordenación de los textos escritos, Romanistisches Jahrbuch 48, 296-315,

GÓMEZ CALDERÓN, B. (2005). "Retórica de la columna personal: una propuesta de análisis." Ínsula, pp.713-714, pp. 15-17.

LÓPEZ EIRE, A. (1999) "Esencia retórica del lenguaje publicitario." En Tópicos: revista de Filosofía, № 17. págs. 129-152

LOUREDA LAMAS, O. (2000) "Sobre un tipo de marcadores discursivos en el español actual.” RILCE, vol. 16, n. 2, pp. 325-342.

NúÑEZ LADEVÉZE, L. (2007) "Sobre el manido tema de la imparcialidad informativa." Revista Asociación Prensa Española, n. 10.

O'HALLORAN, K. (2015). Multimodal digital humanities. In International Handbook of Semiotics, P.P. Trifonas (ed.), 389-415. Netherlands: Springer.

PORTOLÉS LÁZARO, J. (2007) "Las escalas informativas convocadas por "ni” y "ni siquiera" en Revista internacional de lingüística iberoamericana, № 10 págs. 199-220

ROMERA, Á. http://retorica.librodenotas.com/ (Fecha de último acceso 2/10/2017)

\section{BREVE SEMBLANZA DE LAS AUTORAS:}

Aurora García González. Doctora en Comunicación Pública y, profesora titular de Periodismo con acreditación para el cuerpo de Catedráticos (2014) en la Facultad de Ciencias Sociales y de la Comunicación de la Universidad de Vigo. Ha publicado diversos trabajos de investigación en el campo de la comunicación, entre otros: "Cambios tecnológicos en el contexto publicitario: Dinámicas y tendencias en investigación" (2015) Icono 14 
$\mathbf{M}^{\mathrm{a}}$ Lourdes Román Portas. Doctora en Investigación en Comunicación por la Universidad de Vigo y miembro del Grupo de investigación CS1 (ICOM) de la misma Universidad. También es Licenciada en Filología Hispánica y Gallego-portuguesa, ambas por la Universidad de Santiago. Es autora, entre otras obras, de Una aproximación al análisis comparativo del léxico metalingüísitco gallego-español (Edita, 2012).

- Recibido: 00/00/2018

- Aceptado: 00/00/2018

Ámbitos. Revista Internacional de Comunicación, n.40, edición de primavera, 2018. 